\title{
Formel Ontolojiler ve Betimleyici Mantıklar
}

\section{Formal Ontologies and Description Logics}

\author{
${\text { Dilek } \operatorname{Yargan}^{1}}$
}

'Araştırmacı, Berimsel Ontoloji Laboratuvarı, Orta Doğu Teknik Üniversitesi, Ankara, Türkiye

ORCID: D.Y. 0000-0001-9618-6740

Sorumlu yazar/Corresponding author: Dilek Yargan,

Berimsel Ontoloji Laboratuvarı, Orta Doğu

Teknik Üniversitesi, Ankara, Türkiye

E-mail/E-posta: dilek.yargan@gmail.com

Başvuru/Submitted: 03.12.2019

Revizyon Talebi/Revision Requested: 07.12.2019

Son Revizyon/Last Revision Received: 08.12.2019

Kabul/Accepted: 09.12.2019

\section{Atıf/Citation:}

Yargan, Dilek. (2019). "Formel Ontolojiler ve Betimleyici Mantıklar" Felsefe Arkivi- Archives of Philosophy, 51: 271-281.

https://doi.org/10.26650/arcp2019-5119

\section{ÖZET}

Ontoloji tarihine baktığımızda varlığın çeşitli metotlarla incelendiğini görürüz. Geleneksel ontoloji, varlığı varlık olması bakımından inceler ve onu çeşitli kategoriler altında sınıflandırır. Formel ontoloji, tüm varlıklarda ortak olan kategorileri belirler ve varlığı formel dillerle bu kategorileri de kullanarak sınıflandırır. Bununla beraber, otuz yılı aşkın zamandır formel ontolojiler felsefe dışında araştııılıyor ve kuruluyor. Ontolojinin felsefeden ayrılıp, disiplinler arası bir çalışma olmasının nedeni veri ve bilgi yönetiminde gerçekliğe uygun sınıflandırmalar ve standardizasyon yapma gereksinimimizdendir. Bu gereksinimin ardında verinin üssel hızla artışı ve bunun ne insanlar ne de mevcut yöntemler tarafından analizinin imkansızlığı bulunmaktadır. Örneğin, günümüzde her dakika onlarca çalışma yayınlanmaktadır, bilim insanları tüm bu gelişmeleri klasik yöntemlerle takip edememektedir. Bu nedenle, bilgi paylaşım ve üretme süreçlerine makinelerin dahil edilmesi arzusu her zamankinden çok daha fazladır. Bu arzu ise bilginin işlenebilmesi için bizleri yeni modeller geliştirmeye sevk etmiştir. Modellerin oluşturulmasında bilginin standartlaştırılmasının şart olduğu deneyimlenmiştir. Zira, farklı çalışma gruplarının bilgi temsillerindeki taksonomik yapılar, kavram tanımları, alandaki inceleme derinlikleri arasında ciddi farklılıklarla karşılaşılmış, verilerin entegrasyonu dahi mümkün olamamıştır. Bu noktada, ontolojik ilkeler ve yöntemler kullanılarak bilginin seçilmesi, sınıflandırılması ve standartlaştırılması sağlanmıştır. Bu yazımızda, enformasyon sistemleri içinde, felsefi ontolojilerin ilke ve yöntemlerini kullanarak, seçmek, sınıflandırmak ve standartlaştırmak suretiyle alana ait bilgiyi en geniş şekilde kapsayan formel teoriyi olan formel ontolojileri tanıtacağız. Doğal dilin ifade etme gücüne ve yüksek performanslı uslamlama algoritmalarına sahip formel diller ailesi olan betimleyici mantıkları, bu teoriyi makinelerde temsil etmek için kullandığımıza değineceğiz. Ezcümle, bu yazımız, formel ontolojileri ve betimleyici mantıkları bilgi temsili özelinde tanıtacaktır.

Anahtar Kelimeler: Bilgi temsili, formel ontoloji, uygulamalı ontoloji, betimleyici mantıklar, çıkarım

\section{ABSTRACT}

The history of ontology reveals various methodologies that examine being. Traditional ontology studies being qua being and categorizes it. Formal ontology determines the categories that are common to all entities and classifies them with formal languages using these categories as well. However, for over thirty 
years, formal ontologies have been studied and built outside of philosophy. The reason why ontology is separated from philosophy and becomes an interdisciplinary study is due to our need to make classifications and standardization in data and information management in accordance with reality. What lies behind this requirement is the exponential growth of data and the impossibility of analyzing it neither by humans nor by existing methods. For instance, dozens of studies are published every minute, and then scientists cannot follow all these developments with classical techniques. Therefore, the desire that machines should be involved in the processes of sharing and producing knowledge is far higher than ever. This desire, thus, has led us to develop new models for knowledge production. It has been experienced that the standardization of knowledge is essential in the construction of models; for, significant differences were found between taxonomic structures, concept definitions, and different granularity levels in the knowledge representations of various working groups, and even the integration of data was not possible. At this point, the selection, classification, and standardization of knowledge have been guaranteed by using ontological principles and methods. In this article, within information systems, we will introduce the formal ontologies, the formal theory covering the broadest knowledge of the field by selecting, classifying and standardizing it by using the principles and methods of philosophical ontologies. We will mention that we use description logics, a family of formal languages with the expressive power of natural language and high-performance reasoning algorithms, to represent this theory in machines. In essence, this article will introduce formal ontologies and description logics in the realm of knowledge representation.

Keywords: Formal ontology, applied ontology, description logics, knowledge representation, inference

\section{Giriş}

Felsefeciler için "ontoloji” denince akla ilk gelen varlık bilimidir. ${ }^{1}$ Konuyu biraz irdelersek varlık ve yokluk üzerine tartışmalara tanık oluruz. Örneğin, yokluğun var olduğunu söylemenin ona bir varlık atfetmemiz gerektiğini iddia eden görüşlerle karşılaşmamız çok muhtemeldir. Tartışmaları varlığın kabulü üzerinden yaptığımızda da bu kez de karşımıza varlığın neliği sorusu çıkar. Bu eksendeki incelemeler varlığın sınıflandırılmasını amaçlar. Sınıflandırma ise bizi varlık üzerine yaptığımız çalışmalarda başka bir boyuta taşır: Ontoloji tüm varlıklarda ortak olabilecek kategorilerin belirlenip formel olarak ifade edilmesidir. O halde, felsefede varlık iki tür yaklaşımla incelenir: İlki varlığa ait kategorilerin belirlenmesi, yani geleneksel ontoloji, ikincisi ise tüm varlıklarda ortak olan kategorilerin de belirlenmesi, yani formel ontoloji. İki yaklaşım arasında metodolojik farklılık da vardır: Felsefi bir disiplin olarak formel ontoloji hem varlıkların formel sınıflandırmasını hem de gerçekliği ya da dünyayı modellerken kullanacağımız üst düzey kategorileri (kavramlar, parça-bütün, nitelikler, zaman ve mekan ilişkisi gibi) verir. ${ }^{2}$

$\mathrm{Bu}$ yazımızda bilgi temsilinde kullanılmak üzere oluşturulan enformasyon sistemlerindeki

1 Varlık ögrretisi ya da varlık felsefesi de eşit derecede makbuldür.

2 Felsefe tarihinde formel ontoloji kavramı Husserl tarafından ilk kez Logische Untersuchungen eserinde ortaya konulmuştur. Genel olarak formel ontoloji, parça-bütün teorisi, bağımlılık teorisi ve sınır-devamlılık-temas teorisini inceler (Bakınız: Smith, "Basic Concepts of Formal Ontology", Formal Ontology in Information Systems, Ed: Nicola Guarino, 1998, s.19.). Husserl'den günümüze felsefi bir disiplin olarak formel ontoloji farklı şekillerde tanımlanmıştır. Yazımızda, formel ontolojilere bütünsel bir bakış sunduğu için Cocchiarella’nın tanımını kullandık. Ona göre, "formel ontolojiler, varlığa ait tüm biçim ve modlar mantığının sistematik, formel, belitsel gelişimidir" (Cocchiarella, Nino, "Ontology II: Formal Ontology" Handbook of Metaphysics and Ontology, Editörler: Hans Burkhardt ve Barry Smith, Munich: Philosophia Verlag 1991, p.640.). Yukarıdaki tanımımızı incelersek, tanımın ilk kısmı analitik felsefe içindeki geleneksel ontoloji çalışmalarına, ikinci kısmı ise fenomenoloji çalışmalarına yakındır. 
formel ontolojilerden bahsedeceğiz. Anlatmaya felsefeyle başlamamızın tek sebebi formel ontoloji kavramının nereden geldiğini göstermek değildir. Tüm entiteler ${ }^{3}$ için ortak olan kategorilerin doğru belirlenmesi, gerçekliğe en uygun sınıflandırmaların yapılması, kategoriler arası ilişkilerin doğru belirlenmesi, farklı amaçlarla oluşturulmuş sistemler arasındaki geçişin, beraber işlerliği ve bu sistemleri birleştirmenin sağlanması için felsefi çalışmalardan alınan öngörü, ilkeler ve beceriler elzemdir. Bu nedenle felsefi ontoloji bilgisi her zaman ontoloji inşasında gerçekliğin/ dünyanın makineye aktarımı sağlayacak bir araçıı. Bu kısa yazımızın amacı enformasyon sistemlerinde bilgi temsili için kullanılan formel ontolojiler hakkında bilgi vermek ve ardından bu yapay nesnenin makinelerdeki temsili için kullanılan mantık sistemini incelemektir.

\section{Enformasyon Sistemlerindeki Formel Ontolojiler}

Makinelerin hayatımıza girdiği günden bu yana veri, yaşamımızı sürdürmek için en gerekliler listesine, hatta dünyamızın yapı taşlarından biri olarak dört temel elementin ardına eklenmiştir. Verinin toplanması, organizasyonu, işlenmesi farklı tasarımlarla yapılmakta, yaşamın her alanında bu tasarımlar kullanılmaktadır. Örneğin, bilgi yönetim sistemlerinin amacı bilgiyi erişilebilir, işlenebilir ve paylaşılabilir kılmaktır. Yapay zekâ çalışmalarının amacını, yani akıllı bir sistem davranışlarının makineler tarafından sergilenmesini, bu amaçla birleştirdiğimiz de bilgi temsili ortaya çıkar. Zira, makinelerin akıllı bir sistem olarak, bilgiyi işleyebilmesini ve yeni bilgiler üretebilmesini sağlamak en büyük amaçlarımızdandır. İşste, formel ontolojilerin enformasyon sistemlerinde konuşlandığı alan bilgi temsilidir.

Yapay zekâ araşı̧ırmalarının ve günümüzün en önemli uğraşı olan büyük verinin merkezindeki konu olan bilgi temsili, bir alana ait enformasyonun makinelerde çeşitli tasarımlarla işlenebilir hale getirilmesi sürecidir. Uluslararası Bilimsel, Teknik ve Tıbbi Yayınevleri Derneğìnin Kasım 2018 raporuna göre, 2018'de sadece İngilizce yayın yapan dergilerde yayınlanan makale sayısı üç milyon civarındadır. ${ }^{4}$ Önümüzdeki yıllarda \%6'dan fazla büyüme oranında bu sayının artacağı da öngörülebilmektedir. ${ }^{5}$ Bilim dünyasındaki bilgi artışı insan seviyesinde kontrol edilemez, bu nedenle bilim insanlarının elde ettikleri verilerini paylaşamaması ciddi bir sorun haline gelmiştir. O halde, bu konuda yardımına başvuracağımız merci yüksek hızlarda işlem yapan ve günümüzde depolama sıkıntısı olmayan makinelerdir. Ancak, makineler kendi kendilerine bu verileri işleyemeyecekleri için verilerin onların okuyabilecekleri formata dönüştürülmesi ve işlemelerini sağlayacak mimarinin sunulması gerekir. Peki, aynı alan bilgisi araştırmacılar

3 Yaptı̆̆ımız çalışmalarda karşılaşıık ki, "varlık" sözcüğü felsefe odaklı zihinlerde Tanrı ve kategori ile alakalı bilgileri, felsefe dışından olanlarda ise somut nesneleri çağrıştırıyor. "Entite", Latince "varlık" demenin Türkçeleştirilmiş hali. Bu sözcüğü seçme nedenimiz çeşitli çağrışımlardan münezzeh ontolojilerde bulunabilecek her şeyin bu kavramın alında yer alabilmesidir. Elbette ontolojik seçimler bazı varlıkları araştırma konusu olarak alır, ancak burada vurgulamak istediğimiz nokta sayıların, süper kahramanların, Pegasus’un, sürecin, ilişkilerin de birer varlık olarak ontolojiler içinde ele alındığıdır. Ezcümle, bundan sonra ontolojide olabilecek her şeyi "entite" kavramı ile karşılayacağız.

4 International Association of Scientific, Technical and Medical Publishers, The STM Report An overview of scientific and scholarly publishing (Çevrimiçi), www.stm-assoc.org/2018_10_04_STM_Report_2018.pdf, 2018, s.25.

5 A.g.e., s.27. 
tarafından farklı kavramsal düzeylerde modellendiğinde karşımıza ne gibi sorunlar çıkabilir? ${ }^{3}$ Örneğin, alan bilgisine ait kavramlar amaca göre taraflı bir şekilde ele alınmış olabilir. Diğer yandan, niyetler aynı olsa da kavramlar farklı bakış açılarıyla tanımlanmış, hatta aynı kavram başka sözcüklerle ya da farklı kavramlar aynı sözcükle ifade edilmiş olabilir. ${ }^{7}$ Makine işlerliği göz önünde bulundurularak bilginin ifadesinde çeşitli kolaylıklara gidilmiş olabilir ya da farklı sistemlerin bir araya getirilmesinden doğacak kavramsal temsillerin muğlaklı̆̆ karmaşıklaştırabilir. Nihayet, en önemlisi, oluşturulan kavramsal temsil amaca hizmet ederken gerçeklikle bağdaşmayabilir: Tasarımcının kafasındaki dünyanın temsili elbette çok ciddi sıkıntılara gebe olacaktır. Oluşturulacak sistem ilk amacı dışında kullanılamayacak, belki sistem büyüdüğ̈̈nde de amacına hizmet edemeyebilecektir. Tüm bu olasılıklar bize oluşturulan sistemlerin tekrar kullanılabilirliği, birlikte işlerliği, birleştirilebilirliği konularındaki sıkıntılara işaret ederler. Elbette, tek kullanımlık bilgi temsilleri oluşturmak mümkündür, ancak ekonomik değildir. O halde, bilim insanları arasında iletişim sağlayacak ortak bir yapı oluşturmak ve mevcut enformasyonu kullanarak yeni enformasyonu otomatik olarak elde edebilmek amaciyla, üretilen verinin kalitesini arttırmak, veriyi tekrar kullanılmaya uygun şekilde saklamak ve yönetebilmek için üç aşamalı bir süreç izlememiz gerekir: Seçme, sınıflandırma ve standartlaştırma.

Makinelerde bilgi temsili için yapacağımız ilk işlem gerçekliğin belirli bir kısmını temsil etmek için kullanacağımız entiteleri seçmektir. Temsilde kullanılacak entiteleri seçme ilk bakışta pek kolay gözükse de üzerinde belki de en çok düşünülmesi gereken aşamadır. Bunun iki temel nedeni vardır. Her şeyden önce, gerçekliğin kısmi temsilinin tasarımcının kavramsallaştırmasından arınmış olduğundan emin olmak gerekir. ${ }^{8}$ Diğer nokta ise, gerçekliğin kendisi iç içe geçmiş seviyelerin karmaşık bir hiyerarşisi olduğu için çalışma alanımıza düşen entiteleri hangi detay seviyesinde ele almamız gerektiğine de karar vermemiz gerekir. Tasarımcılar daima bilimin ışığında ortaya konulan entiteleri seçmelidirler ve tanımlarını yine bilimden almalıdırlar. Ad hoc temsiller herhangi bir değişiklikte ya ciddi bir revizyondan geçerler ya da onlardan tamamen vazgeçilir. Oysa ki bilgi temsili, alana ait enformasyonun tutarlı ilkelerle gerçekliğin bir kısmının temsili olarak yapılırsa, bu temsil çerçeve olarak alınır ve böylece dengeli bir şekilde bu çerçeve gelişir ve kullanılmaya devam eder.9 Örneğin, iş güvenliğine dair bir ontoloji geliştirirken "gözlük" entitesini sadece bu alana ait bir kavram olarak tanımlamak son derece yanlış olacaktır. Halbuki

6 Takip etmeyi kolaylaştırması için şu örnekleri düşünebilirsiniz: Plüton gezegen kategorisine ya da cüce gezegen kategorisine alınabilir; Süreçlerin zamansal boyutu temsilde ifade edilmemiş olabilir; Su kimyasal formülü üzerinden tanımlanmış olabileceği gibi dünyanın dörtte üçünü kaplayan dört elementten biri olarak tanımlanmış olabilir; Akıl, bir yerde zihin olarak tanımlanmış bir yerde ise zihnin bir yetisi olarak tanımlanmış olabilir.

7 Burada bahsettiğimiz durumlar çok daha geleneksel bilgi edinme, işleme ve tartışma sürecinde de karşımıza çıkar. Biz insanlar arkaplan bilgisine sahip olduğumuz için bağlamdan olası farklılıkları hızla tespit edebiliriz. Böylece kavramları yeniden zihnimizde düzenler ya da en azından muhattabımıza ne demek istediğini sorabiliriz. Ancak, makinelerin arka plan bilgisi olmadığı için bu tür bağlantıları kendisinin kuracağı bir yetisi henüz yoktur. Bu nedenle makinelerdeki temsilimizde apaçık olmalıyız. Bu konuya işaret eden sevgili Berk Yaylım’a çok teşekkür ederiz.

8 Ezcümle, entite seçimlerini gerçekçi [realist] ilkelerle yapmak gerekir. Ontoloji inşasındaki gerçekçi tutumu savunmak yazımızın amaç ve boyutunu aşacağı için bu konuya girmemeyi tercih ediyoruz.

9 Grenon, Pierre. "A primer on knowledge representation and ontological engineering." Applied ontology: An introduction, Editörler: Katherine Munn ve Barry Smith, 2008, s.73. 
“iş güvenliği gözlügüu” olarak gözlük kategorisinden tanımının yapılması gerekir. Bahsedilen ontolojide "gözlük" entitesi iş görebilir, ancak gerçeklik ile uyuşmaz, zira "gözlük" ve "iş güvenliği gözlüğü” entitelerinin tanımları çok farklıdır. Eğer hedefimiz gerçekliğin makinelerde temsili ise, bahsedilen ontoloji içine entitenin kullanımı iş görse bile, gerçeklik/dünya makinelerde temsil edilememiş olur. Bu nedenle, gerçeklikle uyumlu bir bilgi tabanının kurulması tek çaredir. Gerçi, gerçek bir bütün olarak anlaşılamaz. Bizler gerçekliği farklı detay seviyelerinde ve farklı araştırma metotlarıyla kavrarız. Belirli bir alanın bilgisinin temsili söz konusu olunca seçme işlemi dikkatle ve belirli metotlarla yapılır. Belirli bir coğrafyadaki toprak verimliliğini araştıran bilim insanları için o alanın jeopolitik önemi araştırma konularının dışında kalacaktır. Bununla beraber tarım verimliliğini sadece toprakta bulunan mineral özelliklerini inceleyerek bir bilgi tabanı elde edebileceğimiz gibi, araştırmayı daha detaylandırarak toprak alı sularının kimyasal özelliklerinden yerel rüzgarların sıcaklık değişikliklerine kadar toprak verimliliğini etkileyecek özellikleri inceleyerek aynı araştırmayı yapabiliriz. Özetle, bir alanın bilgisine ait farklı detay seviyelerinde olan entiteler gerçekçi bakış açısı ile seçilmelidir. Böylece entitelerin tanımları gerçeklikten gelir. Elde edilen entite yığınını düzenlemek için sınıflandırma yapılır. Sınıflandırma bir alanın sistematik temsilidir. Bu aşamada entiteler mutlaka görev-bağımsız bir şekilde sistematik kategorileştirmeye tabi tutulurlar, ${ }^{10}$ yani entitelerin o alan içindeki özel durumlarına göre değil, entitelerin ontolojik statülerine göre hiyerarşik bir düzen kurulur. ${ }^{11}$ Doğru bir sınıflandırma için, entitelerin doğalarına dair bilgiyi ve hiyerarşiyi kurmada hangi ilkeleri takip etmemiz gerektiğini felsefi ontolojilerden öğreniriz. Bu aşamada yapılacak ilk adım bir taksonomi oluşturmak, yani entiteleri kapsam ilişkisine göre düzenlemektir. Diğer yandan "molekül” hem biyologlar hem de kimyagerler tarafından farklı nedenlerle incelenen bir entitedir. Peki, bu durumda molekülün tanımı neye göre yapılmalıdır? Ya da sınıflandırmada hangi bilimin temel ilkeleri kullanılmalıdır? Smith ve Klagges'in ontolojik bakışaçısalcılık ${ }^{12}$ dedikleri felsefi tutum gerçekliğe ait eşit derecede geçerli farklı görüşlerin olabileceğini ve aynı zamanda bu görüşlerin farklı araçlarla ve biçimlerle ifade edilebileceğini söyler. ${ }^{13}$ Aynı bilim dalı içinde bile gerçekliğin belirli kısımlarını ayrı ayrı çalışan bilim insanlarının çalışmaları arasında nasıl bir uyum yakalanacaktır? Bu çalışmalar nasıl birleştirilebilir? Ya da gerçekliğin aynı kısmını farklı öğe boyunda, yani farklı detay seviyelerinde çalışan bilim insanlarının çalışmaları arasında bir ilişki nasıl kurulacaktır? Bu durumda, gerçekliğin bu iç içe geçmiş seviyelerini bağlayabilecek ve farklı hiyerarşik düzeylerde oluşturulmuş sistemleri birleştirebilecek bir yapının olması zorunludur. Bu yapı standartlaştırılmış bir sınıflandırmadır. Yani, bir önceki aşamanın standartlaştırılması bizim bilgi temsilindeki kavramsal modelimizi verir. Standartlaştırma aşaması artan bilginin makinelerde beraber işlerliği kolaylaştırmak, bilim insanları arasında doğru iletişimi sağlamak, veri entegrasyonunu düzenlemek, farklı formel diller arası geçişe izin vermek için yapılır.

10 Guarino, Nicola. "Formal ontology, conceptual analysis and knowledge representation." International journal of human-computer studies 43, no. 5-6, 1995, s. 627.

11 Örneğin, karın özelliklerinden olan beyaz olma ve soğuk olma farklı kategoriler altında yer almalıdır.

12 Ing. ontological perspectivism.

13 Smith, Barry ve Bert Klagges. "Bioinformatics and Philosophy" Applied ontology: An introduction, Editörler: Katherine Munn ve Barry Smith, 2008, s.24, s.26. 
Bu sürecin adına, yani seçmek, sınıflandırmak ve standartlaştırmak suretiyle alana ait entiteleri en geniş şekilde kapsayan formel teoriye formel ontoloji diyoruz. Formel ontolojiler, felsefi ontolojiler ışığında enformasyon sistemlerinde verinin saklanması ve yönetime dair yöntemlerin geliştirilmesini sağlamak için oluşturulan araçlardır. İlk bakışta ontoloji kurmak felsefi bir uzmanlık gerektirmeyen teknik bir süreç olarak gözükebilir. Diğer yandan, her şeyden önce, ontoloji inşasında içeriğin felsefi analizi zorunludur ve felsefi ontolojik teorilerin ışı̆̆ında bilgi temsil sisteminin altyapısı böyle kurulur. ${ }^{14}$ Örneğin, bilgi tabanımızı oluşturacak tüm verimiz "Elma kırmızıdır" ifadesinden gelsin. Bu durumda seçme aşaması, iki entite ve bir ilişki (elma, kırmızı, olmak) ya da bir entite ve onun özelliği (elma, kırmızı olmak) olarak tasarlanabilir. Sınıflandırmaya gelince, buradaki entitelerin zaman içinde değişip değişmemelerine göre de kategorik bir ayrım yapmak zorunludur. Bu itibarla, elma zamanın her biriminde değişmen bir kimlikle mi yoksa zaman içinde değişimlere uğrayan kimlikler bütünü olarak mı ele alınmalıdır? ${ }^{15}$ Standartlaştırma ise bir önceki aşamalarda aldığımız kararlar doğrultusunda belirlenir. Bu yüzden, makineler ile gerçeklik arasında uzlaşımı sağlayan felsefi ontolojik ilkeler kullanılarak, enformasyon-teknolojik süreçler, titiz ve apaçık tanımlamalar yapılarak entitelere dair her şeyi kapsayan bu teori ile yapilır. ${ }^{16}$

\section{Formel Ontolojilerin Uygulanması ya da Uygulamalı Ontolojiler}

Şimdi bir noktaya açıklık getirelim: Literatürde formel ontoloji iki farklı disiplin için kullanılıyor. Bunlardan biri daha önce bahsettiğimiz felsefi bir disiplin olarak formel ontoloji, diğeri ise enformasyon sistemlerinde kullanılmak üzere geliştirilen bir araç olarak formel ontolojidir. Enformasyon sistemlerinde formel ontolojilerin önemi güçlü bir bilgi temsili sunmalarından ve otomatik enformasyon sistemleri için kullanılmalarından gelir. Kullanmak sözcüğ̈̈ formel ontolojilerin alana uygulanması demek olduğundan elde edilen formel teoriye uygulamalı ontoloji ${ }^{17}$ de denir. O halde, uygulamalı ontolojiyi şu şekilde de tanımlayabiliriz: Felsefi ontolojiden aldığı ilke ve metotlarla bilimsel araştırmaların sonuçlarını daha etkin şekilde temsil etmek amacıyla kullanılan yazılımlardır. ${ }^{18}$ Uygulamalı ontolojilerin inşasındaki nedenler biz ontologları farklı seçme, sınıflandırma ve standartlaştırma tekniklerine sevk eder. Bu da bizi uygulamalı ontoloji çeşitlerine getirir. Uygulamalı ontolojiler alan ve alan bağımsız olmak üzere ikiye ayrılırlar. Belirli bir alanın bilgi temsilini sunan alan ontolojileri uygulama ontolojisi ${ }^{19}$ ve referans ontolojisi ${ }^{20}$ olarak karşımıza çıkarlar. Uygulama ontolojileri bir amaç için tasarlanmış ve bu amaç doğrultusunda bilgi temsilinde belirli kısıtlamalarına göz yumulmuş bir bilgisayar

14 Grenon, 2008, s.69.

15 Formel ontolojilerin temel kategorilerinden biri entiteleri sürekli nesne [continuant] ya da oluşlanmış [occurrent] olarak belirlemektir. Sürekli nesneler var oldukları zaman içinde kendi kimliklerini koruyan nesnelerken, oluşlanmışlar/meydana gelen entiteler zaman içinde oluşturdukları için süreç olarak düşünülürler. O halde, elma, sağduyuya göre, sürekli bir entitedir.

16 Smith ve Klagges, 2008, s. 27.

17 Ing. Applied ontology

18 Bu nedenle, enformasyon sistemlerinde formel ontoloji ve uygulamalı ontoloji birbirleri yerine kullanılırlar. Hatta kısaca ontoloji de denir.

19 İng. Application ontology

20 Ing. Reference ontology 
uygulamasıdır. Referans ontolojisi ise bir alana ait bilginin en güncel halinin olabildiğince doğru ve kesin temsil edilmesidir. Bu nedenle, referans ontolojilerini uygulama ontolojilerinin oluşturulması için kullanılacak bir altyapı olarak düşünebiliriz. Örneğin, gen ontolojisini referans ontoloji olarak genetik hastalıklar ontolojisinin kurulmasında kullanabiliriz. Uygulamalı ontolojilerin alan-bağımsız olanlarına ise üst-düzey ontolojiler ${ }^{21}$ denir. Üst-düzey ontolojiler tıpkı felsefi formel ontolojiler gibi varlığa ait tüm kategorilerin sınıflandırılmasını hedeflerler. Öyle ki, bir üst-düzey ontolojinin hiyerarşik yapısı kullanılarak alan ontolojilerinin entiteleri tanımlanır. "Elma kırmızıdır" örneğimizdeki entitelerden "elma” sürekli nesneler kategorisi altında yer almalıdır. Sonuç olarak, üst-düzey ontolojileri de referans ve/veya uygulama ontolojisi oluşturmak için bir çerçeve olarak kullanırız. Buna en güzel örnek OBO'dan gelir. ${ }^{22}$ OBO birlikte işlerliğe sahip biyoloji ve biyomedikal alanlarda referans olarak kullanılmak üzere ontolojiler geliştiren girişimin adıdır. Buradaki referans ontolojilerin oluşturulması için bir üst-düzey ontoloji olan Temel Formel Ontoloji ${ }^{23}$ kullanılır. O halde, biyoloji ve/veya biyomedikal alanında belirli türden bir bilgisayar uygulamasında kullanılmak üzere oluşturulacak bir uygulama ontolojisi BFO ile hazırlanmış bir referans ontolojisini kullanır. Tekrar etmek gerekirse, bu şekilde alanın seçilen entiteleri standartlaşmış olarak sınıflandırılırlar.

\section{Formel Ontoloji ve Mantık}

Buraya kadar formel ontolojilerin enformasyon sistemlerinde ne olduklarını kısaca anlattık. Şimdi sıra formel ontolojilerin mantık ile ilişkisini incelemeye geldi. Felsefi formel ontolojilerin tanımını verirken formelleştirmeden bahsetmiştik; buradaki formel yapı mantık sistemlerini de kapsamaktadır. Mantık sistemleri bilgi temsilinde yapay zekânın ilk yıllarından bu yana kullanılagelmiştir. ${ }^{24} \mathrm{Bu}$ sistemlerden en popüleri doğal dile yakın yüksek ifade gücüne sahip olduğundan birinci dereceden mantıktır. Ancak, birinci dereceden mantığın en büyük sorunu berimsel karmaşıklıktır. Her şeyden önce birinci dereceden mantık karar verilemeyen yapıya sahiptir; yani birinci dereceden mantıkla ifade edilen bir yapıdan çıkarım yapıp yapamayacağımızı bilmenin mümkün olmadığı durumlar vardır. Berimsel olarak bu asla istemediğimiz bir durumdur. Buna ek olarak, birinci dereceden mantığın ontolojik seçimleri yoktur. Guarino, birinci dereceden mantığın ontolojik seçimler bakımından tarafsız olmasının bilgi temsili açısından bir dezavantaj olarak görür, çünkü bu durum bilgi temsil dillerinin gerçekliğin yapısını $a$ priori olarak göstermesine ve ontolojik seçimleri kullanıcıların belirlemesine izin verir. ${ }^{25}$ Açıkçası, entitelerin seçilmesi, sınıflandırılması aşamalarında gerçeklik ile örtüşecek yapıların formel dilde temsilden önce ya da beraberinde belirlenmesi, formel dilin doğrudan ontolojik seçimlerle gerçekliği ifade etmesini sağlar. Bu nedenler birinci dereceden mantığın enformasyon üzerinden yeni çıkarımlarda bulunmak için kullanışsızlığını belirtir. Ancak, bilgi temsilindeki deneyimler

21 Ing. Upper-level ontology

22 Açık Biyoloji ve Biyomedikal Ontoloji Dökümevi [The Open Biological and Biomedical Ontology (OBO) Foundry] ; http://www.obofoundry.org.

23 Ing. Basic Formal Ontology, BFO.

24 Ayrıntılar için bknz: Lifschitz, Vladimir, Leora Morgenstern, ve David Plaisted. "Knowledge representation and classical logic." Foundations of Artificial Intelligence 3, 2008, ss.3-88.

25 Guarino, 1995, s.9. 
birinci dereceden mantığı bütün bir paket olarak almanın gerekmediğini, belirli kısımlarının seçilerek berimsel karmaşıklığa düşmeden özelleşmiş çıkarım teknikleri geliştirilebileceğini gösterdi. ${ }^{26}$ Yapay zekâda bilgi temsili çalışmaları gereken standardizasyonun gerçekleşmesi için klasik mantığın yetersizliğini bertaraf etmek amacıyla, bu alana özgü notasyon ve yapıya haiz bir mantık sistemini, doğal dilin ifade etme gücüne sahip ve yüksek performanslı uslamlama algoritmaları olan formel bir dil olarak geliştirmeyi amaçladı. Nihayetinde karşımıza betimleyici mantıklar çıktı. ${ }^{27}$ Burada "mantıklar" dememizin nedeni, biraz önce söylediklerimizden de çıkarılabileceği gibi, birinci dereceden mantığın berimsel karar verilebilir kısımlarının bir ailesi olmasıdır. Bununla beraber, betimleyici mantıklar bilgi temsilinde operatör zenginliği ile de birinci dereceden mantığın ötesine geçerler: Betimleyici mantıkların birinci dereceden mantığın sahip olduğu mantık kurucularına, örneğin değilleme eklemi, tikel-evetleme eklemi, sahiptir; hatta birinci dereceden mantığın sahip olmadığı rol özelliklerine de sahiptir, örneğin geçişli ve ters rol. Bunlar çıkarsama sistemlerinde betimleyici mantığın daha fazla enformasyon üretmesini sağlayacak yapılardır. Son olarak, Guarino'nun işaret ettiği formel dilin ontolojik seçimleri de içermesi koşulu betimleyici mantıklar tarafından sağlanır. Böylece, betimleyici mantıklar ile alana ait gerçeklik formel olarak ontolojik seçimlerle temsil edilir. Böylece modelin kendi içindeki tutarlılığı gerçeklik ile tutarlılığını devam ettirecektir. Şimdi ontolojik seçimleri bünyesinde bulunduran bu dili biraz yakından tanıyalım.

Betimleyici mantıklar alan bilgisini en temelde iki bileşen üzerinden temsil ederler: T-Kutusu ve A-Kutusu. ${ }^{28}$ T-kutusu alana ait terminolojik yapıları temsil ederken, A-Kutusu alana özel savları temsil eder. ${ }^{29}$ Bu iki bileşen bir araya geldiğinde de alana ait bilgi tabanını elde etmiş oluruz. ${ }^{30}$ Aile kurumuna ait bir bilgi tabanı oluşturmak istediğimizde "Anne çocuğu olan kadındır.", "Dede, çocuğu anne ya da baba olan erkektir", "Her çocuğun bir annesi vardır" gibi en temel ifadeler T-Kutusunda formel bir dille temsil edilir. ${ }^{31}$ A-Kutusunda "Hülya bir annedir.", "Yüksel Berk'in babasıdır." gibi ilgili bilgi tabanında bulunan tikeller yine formel olarak temsil edilir. Bu itibarla, bilgi tabanı oluştururken, ilk önce atomik kavramlar ve roller belirlenmeli, ardından bu kavram ve roller kullanılarak alanın en önemli yapıları formel olarak T-Kutusunda belirtilmeli, son olarak, ontolojiye ait tikeller ile T-Kutusundaki yapılar kullanılarak A-Kutusu oluşturulmalıdır. Tüm bu süreç tamamlandığında elimizdeki bilgi tabanı üzerinden uslamlama yapabiliriz. Betimleyici mantıklar, hem T-Kutusunda hem de A-Kutusunda uslamlama yapma imkanını bize tanır. Diğer bir deyişle bu iki yapının ayrı ayrı tutarlılığını inceleyebileceğimiz ve onlara ait ifadeleri kullanarak çıkarımlarda bulunabileceğimiz gibi, bilgi tabanının da tutarlılığını inceleyebiliriz ve bilgi tabanından çıkarımlarda bulunabiliriz. Hem T-kutusunun formel ifadesinde hem de

26 Brachman, Ronald J., ve Hector J. Levesque. Readings in knowledge representation. Morgan Kaufmann Publishers Inc., 1985.

27 Ing. Description logics.

28 Sirasiyla, İng. T-Box ve A-Box.

29 İngilizce açılımları "Terminological Box" ve “Assertion Box" olan bu ifadeleri sırasıyla Türkçeye "Terimsel Kutu” ve "Açıklama Kutusu" olarak çeviriyoruz.

30 Bilgisayar bilimlerindeki kavramlara aşina olanlar için T-Kutusunu veritabanı şemasına, A-Kutusunu ise veritabanındaki örneklere benzetebiliriz.

31 Ek'e bakınız. 
çıkarım sürecinde betimleyici mantıklardan hangi mantık operatörlerinin kabul edildiğini önceden bilmemiz gerekir. Okuyucuya karmaşık gelebilecek bu sistemi bir örnekle açıklamaya çalışalım. Ontoloji kurarken entitelerin seçilmesinden ve sınıflandırılmasından, ilişkilerin belirlenmesinden söz etmiştik. Betimleyici mantıklarda da T-kutusunu oluşturmak için atomik kavramların ve rollerin belirlenmesinden ve bu kavramlar ve rolleri kullanarak diğer kavram ve rolleri oluşturduğumuzu söyledik. Bu tesadüf olmayan paralellik ontoloji inşasındaki formel dilin betimleyici mantıklar olduğunu açıkça ortaya koyar. Ontoloji inşasında kullanılan betimleyici mantıklar dili Web Ontoloji Dili, OWL'dur. ${ }^{32}$ OWL şu kurucuların olduğu sistemidir: ${ }^{33}$ Atomik değilleme, kavram kesişimi, değer kısıtlama, tikel kısıtlama -ki buraya kadar olan kısma Genel Tümleyenli Öznitelik Dili denir-, geçişli roller, nominallerden oluşan bir kural kutusu, ters roller ve niceleyici sayal sınırlamalar. ${ }^{34} \mathrm{Bu}$ örnek bize şunu göstermektedir: Modellenecek yapıya uygun betimleyici mantıklar öyle seçilmelidir ki kullanılacak dilin ifade gücü ile uslamlamanın karmaşıklığı arasındaki en başarılı denge bulunsun. Başka şekilde söylersek, entiteler optimum sayıdaki atomik kavramlar ve roller ile, aksiyomlar ise bilgi tabanını temsil edebilecek optimum sayıda betimleyici kurucular ile oluşturulmalıdır. O halde, araştırmacılar, karar verme süreçlerinin her zaman sonlandığı ve karmaşıklığın az olduğu ve bunun yanında kullanılan betimleyici mantıkların doğal dile yakın bir ifade gücünde olduğu bir modellemenin peşindedirler.

\section{Sonuç}

Ontoloji tarihine baktığımızda varlığın çeşitli metotlarla incelendiğini görürüz. Geleneksel ontoloji, varlığı varlık olması bakımından inceler ve onu çeşitli kategoriler altında sınıflandırır. Formel ontoloji, tüm varlıklarda ortak olan kategorileri belirler ve varlığı formel dillerle bu kategorileri de kullanarak sınıflandırır. Bununla beraber, otuz yılı aşkın zamandır formel ontolojiler felsefe dışında araştırılıyor ve kuruluyor. Ontolojinin felsefeden ayrılıp, disiplinler arası bir çalışma olmasının nedeni veri ve bilgi yönetiminde gerçekliğe uygun sınıflandırmalar yapma gereksinimimizdendir. Bu itibarla, bilgi saklama, yayma ve üretme alanlarındaki başarıları, formel ontolojileri bilgi temsilinde en çok başvurulan araçlardan biri yapmıştır. Betimleyici mantıklar ise hem doğal dile yakın ifade etme güçleri hem de uslamlama yöntemlerindeki yüksek performans sayesinde formel ontolojiler için en uygun formel dildir. Betimleyici mantıkları diğer formel dillerden üstün tutacak bir diğer özellik de betimleyici mantık çalışmalarında teori ile pratiğin el ele gitmesidir. Teorik çalışmalar uygulamaları için uygun ortamı derhal bulur, pratikteki ihtiyaçlar teorik araştırmalara yön verebilir. Örneğin, teorik çalışmalarda formel sistemdeki karmaşıklık çalışılırken, pratikte optimizasyon teknikleri üzerine çalışmalar sürdürülür. Velhasıl, günümüz felsefecilerin ve mantıkçıların otomatik enformasyon sistemleri için gerçekliğin temsilini en doğru ve net biçimde verecek hiyerarşik yapının ve/veya bu yapıdan doğru çıkarımlar yapabilecek formel dillerin geliştirilmesiyle ilgilenmeleri dilenir.

32 Ing. Web Ontology Language.

33 OWL'un OWL, OWL-Lite, OWL 2-RL gibi bir çok çeşidi bulunmaktadır. Bu yazımızda son versiyonları kapsayan OWL 2'den bahsedilmektedir. Detaylı bilgi için: https://www.w3.org/OWL.

34 Ek'e bakınız. 
Ek: Bu kısımda betimleyici mantıkların formel yapısına dair fikir vermesi açısından kısa bilgiler sunulacaktır.

Bilgi tabanımızda olmasını istediğimiz aile ontolojisine ait bazı ifadeleri T-Kutusu ve A-Kutusunda tanımlayalım.

T-Kutusu:

Kadın

çocuğuVar

Erkek $\equiv \neg$ Kadın

Kadın $\sqcap$ Erkek $\sqsubseteq \perp$

Anne $\equiv \exists$ çocuğuVar.Kadın

A-Kutusu:

Anne(HÜLYA)

çocuğuVar(HÜLYA, BERK)

Olası çıkarım: $\mathrm{q}(\mathrm{x})=\operatorname{Kad} ı n(\mathrm{x}) ; \mathrm{x}=\{\mathrm{HÜLYA}\}$

Aşağıdaki tablo betimleyici mantıklardan oluşan OWL'un yapısını gösterir.

Tablo 1

OWL'da Bulunan Betimleyici Diller

\begin{tabular}{|c|c|c|}
\hline Sentaks & Semantik & Terminoloji \\
\hline A & $\mathrm{A}^{y} \sqsubseteq \Delta^{y}$ & atomik kavram \\
\hline $\mathrm{r}$ & $\mathrm{r}^{y} \sqsubseteq \Delta^{y} \times \Delta^{y}$ & atomik rol \\
\hline $\mathrm{C}, \mathrm{D}$ & $\mathrm{C}^{y} \sqsubseteq \Delta^{y}$ & karmaşık kavram \\
\hline $\mathrm{T}$ & $\Delta^{y}$ & tümel kavram \\
\hline$\perp$ & $\varnothing$ & taban kavram \\
\hline$\neg \mathrm{C}$ & $\Delta^{y} \backslash C^{y}$ & kavram tümleyeni \\
\hline$C \sqcap \mathrm{D}$ & $\mathrm{C}^{y} \sqcap \mathrm{D}^{y}$ & kavram kesişimi \\
\hline$C \sqcup \mathrm{D}$ & $\mathrm{C}^{y} \sqcup \mathrm{D}^{y}$ & kavram birleşimi \\
\hline$\exists \mathrm{r} . \mathrm{C}$ & $\left\{\mathrm{x} \mid(\exists \mathrm{y})\left((\mathrm{x}, \mathrm{y}) \in \mathrm{r}^{y} \wedge \mathrm{y} \in \mathrm{C}^{y}\right)\right\}$ & tikel kısıtlama \\
\hline$\forall$ r.C & $\left\{\mathrm{x} \mid(\forall \mathrm{y})\left((\mathrm{x}, \mathrm{y}) \in \mathrm{r}^{y} \Rightarrow \mathrm{y} \in \mathrm{C}^{y}\right)\right\}$ & tümel / değer kısıtlama \\
\hline geçişli(r) & $\mathrm{x}, \mathrm{y}, \mathrm{z}, \in \Delta^{y}$ ise $(\mathrm{x}, \mathrm{y}) \in \mathrm{r}^{y}$ ve $(\mathrm{y}, \mathrm{z}) \in \mathrm{r}^{y}$ ise $(\mathrm{x}, \mathrm{z}) \in \mathrm{r}^{y}$ 'dir. & geçişli rol \\
\hline$a_{1}, a_{2}, \ldots, a_{n}$ & $\left\{\mathrm{a}_{1}, \mathrm{a}_{2}, \ldots, \mathrm{a}_{\mathrm{n}}\right\}^{y}=\left\{\mathrm{a}_{1}^{y}, \mathrm{a}_{2}^{y}, \ldots, \mathrm{a}_{\mathrm{n}}^{y}\right\}$ & nominaller \\
\hline $\mathrm{r}^{-}$ & $\left\{(\mathrm{y}, \mathrm{x}) \in \Delta^{y} \times \Delta^{y} \mid(\mathrm{x}, \mathrm{y}) \in \mathrm{r}^{y}\right\}$ & ters rol \\
\hline$\leq \mathrm{n}$ r.C & $\left\{\mathrm{x} \in \Delta^{y} \|\left\{\mathrm{y} \in \Delta \mid(\mathrm{x}, \mathrm{y}) \in \mathrm{r}^{y}\right.\right.$ ve $\left.\left.\mathrm{y} \in \mathrm{C}^{y}\right\} \mid \leq \mathrm{n}\right\}$ & \\
\hline$\geq \mathrm{n}$ r.C & $\left\{\mathrm{x} \in \Delta^{y} \|\left\{\mathrm{y} \in \Delta \mid(\mathrm{x}, \mathrm{y}) \in \mathrm{r}^{y}\right.\right.$ ve $\left.\left.\mathrm{y} \in \mathrm{C}^{y}\right\} \mid \geq \mathrm{n}\right\}$ & alar \\
\hline
\end{tabular}


Finansal Destek: Bu makaleyi ortaya çıkaran tüm akademik faaliyetler Berimsel Ontoloji Laboratuvarı tarafından desteklenmiştir.

\section{Kaynaklar}

Brachman, Ronald J., ve Hector J. Levesque. Readings in knowledge representation. Morgan Kaufmann Publishers Inc., 1985.

Cocchiarella, Nino, "Ontology II: Formal Ontology" Handbook of Metaphysics and Ontology, Editörler: Hans Burkhardt ve Barry Smith, Munich: Philosophia Verlag 1991, ss. 640-647.

Grenon, Pierre. "A primer on knowledge representation and ontological engineering." Applied ontology: An introduction, Editörler: Katherine Munn ve Barry Smith, 2008, ss. 57-84.

Guarino, Nicola. "Formal ontology, conceptual analysis and knowledge representation." International journal of human-computer studies 43, no. 5-6, 1995, ss. 625-640.

International Association of Scientific, Technical and Medical Publishers, The STM Report An overview of scientific and scholarly publishing, Beşinci Baskı, (Çevrimiçi), https://www.stm-assoc.org/2018_10_04_ STM_Report_2018.pdf, 2018.

Lifschitz, Vladimir, Leora Morgenstern, ve David Plaisted. "Knowledge representation and classical logic." Foundations of Artificial Intelligence 3, 2008, ss.3-88.

OBO, Açık Biyoloji ve Biyomedikal Ontoloji Dökümevi [The Open Biological and Biomedical Ontology (OBO) Foundry] (Çevrimiçi) http://www.obofoundry.org. Erişim: 23 Kasım 2019.

Smith, Barry "Basic Concepts of Formal Ontology", Formal Ontology in Information Systems, Editör: Nicola Guarino, IOS Press, 1998, ss.19-28.

Smith, Barry ve Bert Klagges. "Bioinformatics and Philosophy" Applied Ontology: An introduction, Editörler: Katherine Munn ve Barry Smith, 2008, ss.21-37.

Smith, Barry, ve Werner Ceusters. "Ontological realism: A methodology for coordinated evolution of scientific ontologies." Applied Ontology 5.3-4, 2010, ss. 139-188. 
